\title{
Platypnea-Orthodeoxia Syndrome After Complicated Cholecystectomy: An Unsuspected Diagnosis
}

\section{Síndrome de Platipneia-Ortodeoxia Após Colecistectomia Complicada: Um Diagnóstico Inesperado}

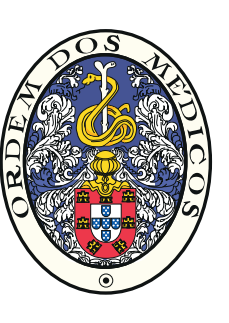

\author{
Catarina QUEIRÓS $\square^{1}$, Elsa FRANCISCO ${ }^{2}$, João ALMEIDA ${ }^{3}$ \\ Acta Med Port 2017 Nov;30(11):827-830 - https://doi.org/10.20344/amp.8700
}

\begin{abstract}
A 65-year-old woman with no significant prior medical history presented, in the postoperative course of a complicated cholecystectomy, several episodes of arterial desaturation. Pulmonary embolism was repeatedly suspected, but there was no evidence of pulmonary thrombus on the chest computed tomography angiographies obtained. As these episodes were mainly induced by postural changes, a platypnea-orthodeoxia syndrome was suspected. A transthoracic echocardiogram was performed and revealed a patent foramen ovale. A transesophageal echocardiography confirmed the presence of a significant right-to-left shunt exacerbated by the Valsalva manouver. The defect was repaired using a percutaneous transcatheter technique with complete resolution of the condition.

Keywords: Cholecystectomy; Dyspnea; Foramen Ovale, Patent; Hypoxia; Syndrome
\end{abstract}

\section{RESUMO}

Doente do sexo feminino, 65 anos de idade, sem antecedentes pessoais relevantes, apresentou no pós-operatório de uma colecistectomia complicada diversos episódios de dessaturação arterial. Suspeitou-se repetidamente de tromboembolismo pulmonar, no entanto as diversas angio-tomografias computorizadas obtidas nunca revelaram a presença de trombos no leito vascular pulmonar. Atendendo a que os episódios de dessaturação eram maioritariamente despoletados por alterações posturais, foi levantada a hipótese de se tratar de uma síndrome de platipneia-ortodeoxia. Foi realizado ecocardiograma transtorácico, que revelou um foramen oval patente; o ecocardiograma transesofágico confirmou a presença de um shunt direito-esquerdo significativo, exacerbado pela manobra de Valsalva. O defeito foi reparado através de uma técnica transcatéter, com resolução completa do quadro clínico.

Palavras-chave: Colecistectomia; Dispneia; Forame Oval Patente; Hipoxia; Síndrome

\section{INTRODUCTION}

Platypnea-orthodeoxia syndrome (POS) is a rare condition characterized by dyspnea and arterial oxygen desaturation induced by the upright position and relieved when supine. By 2012, only 188 patients had been described with this syndrome,${ }^{1}$ making the diagnosis challenging and time-consuming. Although the pathophysiology of this entity remains somewhat uncertain, ${ }^{2}$ there are basically three recognized etiologies: cardiac conditions with intracardiac shunting, pulmonary diseases with ventilation/perfusion mismatch and hepatic entities with pulmonary arteriovenous shunts. ${ }^{1,3}$ Among these potential causes, cardiac conditions are the most frequently associated with this syndrome, ${ }^{4}$ with patent foramen ovale (PFO) being the most common cause of intracardiac shunting, followed by atrial septal defects and atrial septal aneurysms. ${ }^{5}$ Herein we report a case of a patient who developed POS after a complicated cholecystectomy, which was found to be caused by a PFO and promptly resolved with a percutaneous transcatheter closure of the defect.

\section{CASE REPORT}

A 65-year-old woman, with no significant prior medical history, presented in the emergency department with acute cholecystitis. A laparoscopy cholecystectomy was performed. The postoperative course was complicated by a biliary fistula driven by a lesion of the common hepatic duct. Due to this complication, a second surgical intervention was needed to perform a Roux-en-Y hepaticojejunostomy, which was performed two weeks after the first procedure.

After both the first and the second surgery she presented several episodes of desaturation, (peripheral oxygen saturation dropping to $70 \%-80 \%$ ) most of them associated with postural changes and positioning. Pulmonary embolization was repeatedly suspected and various chest computorized tomography (CT) angiographies were performed, but those were always normal. The chest x-ray showed an elevation of the right diaphragmatic hemi-cupula compatible with complications of the surgical procedure (Fig. 1), as the patient presented with a right subphrenic bile collection. The electrocardiogram was normal. The findings of an improvement in the arterial blood gas test with recumbence $(\mathrm{PaO} 2$ raised from 39 while seated to $71 \mathrm{mmHg}$ when lying and arterial oxygen saturation raised from 72 while seated to $99 \%$ when lying) raised suspicion of POS.

In order to look for the cause of this condition, a transthoracic echocardiogram was performed, showing abundant passage of agitated saline contrast from the right to the left atria (Fig. 2), suggesting the presence of a patent foramen ovale. Subsequently, the patient underwent

1. Serviço de Medicina Interna. Centro Hospitalar de Vila Nova de Gaia/Espinho. Vila Nova de Gaia. Portugal.

2. Serviço de Cirurgia Geral. Centro Hospitalar de Vila Nova de Gaia/Espinho. Vila Nova de Gaia. Portugal.

3. Serviço de Cardiologia. Centro Hospitalar de Vila Nova de Gaia/Espinho. Vila Nova de Gaia. Portugal.

$\triangle$ Autor correspondente: Catarina Queirós. catarina.squeiros@gmail.com

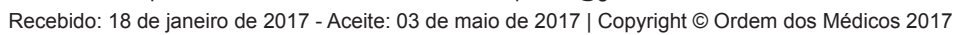




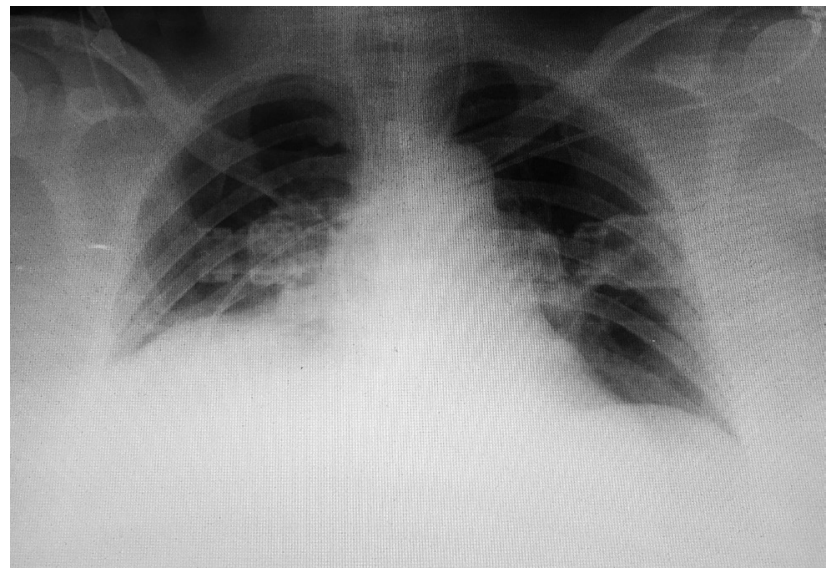

Figure 1 - Postoperative chest $\mathrm{x}$-ray showing an elevated right hemidiaphragm compatible with complications of the surgical procedure

a transesophageal echocardiogram, which confirmed the presence of the shunt; an agitated saline contrast test was performed again, demonstrating a significant right-toleft shunt (Fig.s 3A and 3B). A percutaneous transcatheter closure of the defect with an amplatzer multifenestrated septal occluder was undertaken (Fig. 4), with total abolition of the shunt. The patient was then submitted to a postural change test to confirm the resolution of the condition, presenting an arterial oxygen saturation of $99 \%$ while seated, and was discharged on the following day, after a total of two months of hospitalization.

In the follow-up visit, three months after the procedure, the patient was totally asymptomatic, with an arterial oxygen saturation of $99 \%$ when lying and while seated, confirming the effectiveness of the intervention undertaken.

\section{DISCUSSION}

Among the several conditions associated with POS, cardiac causes with right-to-left shunting are the most common $^{4}$ and require an anatomical and a functional component. ${ }^{6}$ The anatomical defect is most commonly a $\mathrm{PFO}$, but this causes a left-to-right shunt in the absence of elevated pulmonary pressures; therefore, the functional component is responsible for the inversion of the shunt, redirecting venous blood into the systemic circulation especially when the patient assumes an upright position. ${ }^{6}$ This functional defect is usually associated with an abnormal repositioning or deformation of the right atrium with subsequent redirection of blood from the inferior vena cava into the anatomical defect, as described in a case of POS secondary to the liver regeneration that occurred after a lobectomy. ${ }^{7}$

As mentioned before, POS is usually due to one of three conditions: intracardiac shunting, ventilation/perfusion mismatch or pulmonary arteriovenous shunts. ${ }^{1,3}$ Given that our patient did not show any evidence of pulmonary or hepatic disease and the literature states that intracardiac shunting is the most common cause for this syndrome, we directed our investigation towards a cardiac etiology.

In our case we clearly found the anatomical defect, a PFO suggested by transthoracic echocardiography and confirmed by a transesophageal echocardiography. What is not so clear is the functional component responsible for the

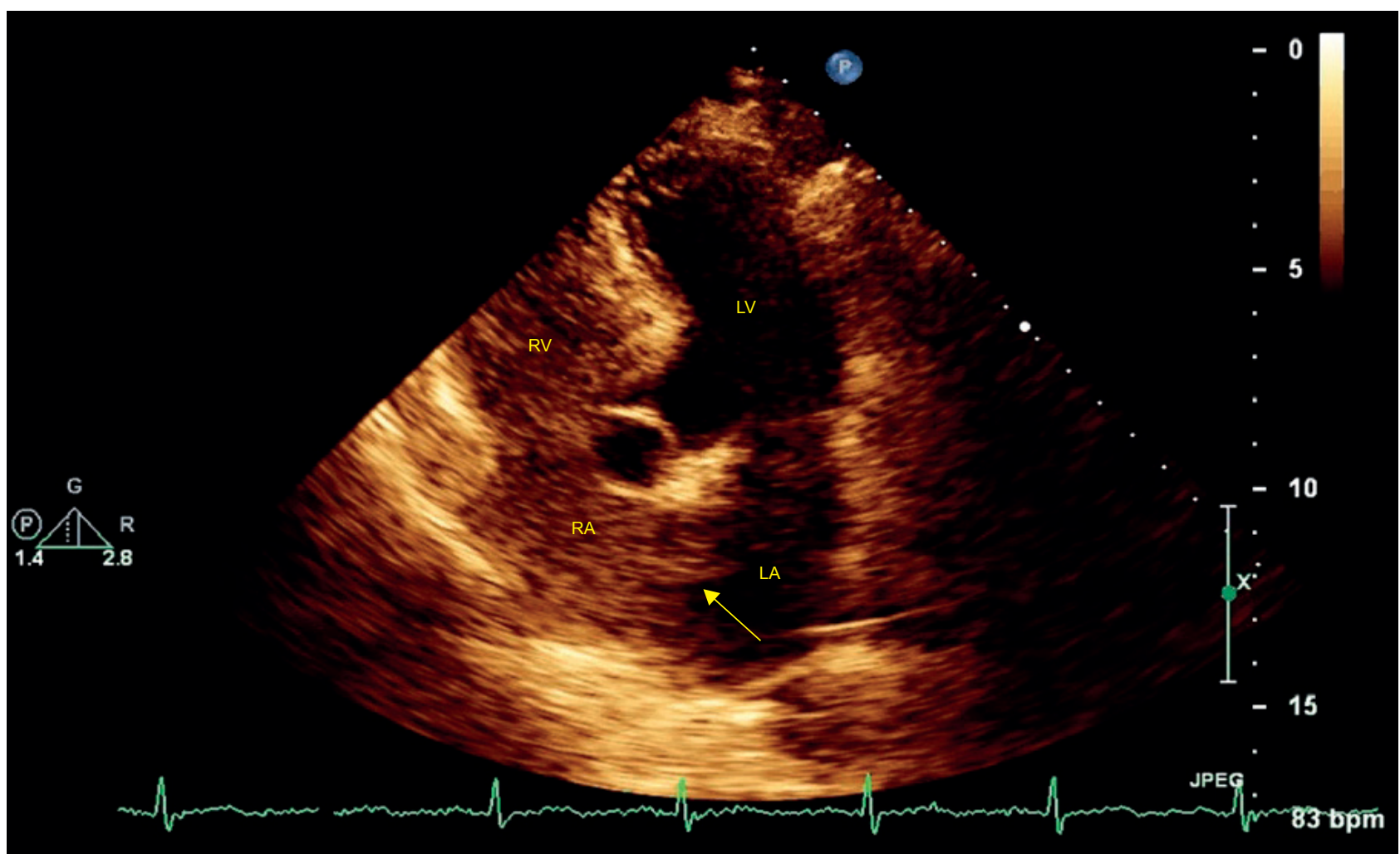

Figure 2 - Transthoracic echocardiography apical 5-chamber view showing passage of contrast from the right to the left atria through the patent foramen ovale (arrow).

RV: Right ventricle; LV: Left ventricle; RA: Right atrium; LA: Left atrium 

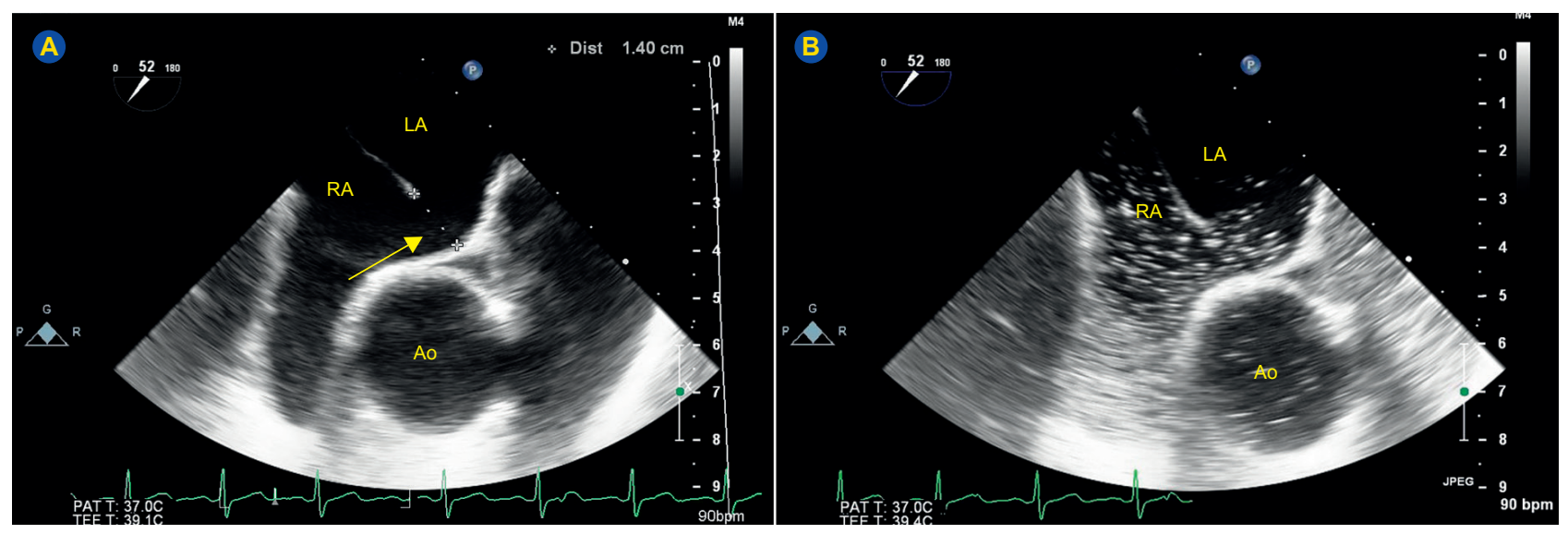

Figure $3-(\mathrm{A})$ visualization of the foramen ovale (arrow) by transoesophageal echocardiography (retroaortic projection). (B) extensive passage of contrast material (agitated saline) through the patent foramen ovale, in the same projection.

LA: Left atrium; RA: Right atrium; Ao: Aorta

presence of a right-to-left shunt. One possible explanation is that the complications related to the surgery distorted the normal toracoabdominal anatomy, as evidenced by the elevation of the right diaphragmatic hemi-cupula in the chest X-ray. This elevation could eventually lead to a displacement of the heart to the left and into a more horizontal position, therefore resulting in a direct alignment between the inferior vena cava and the PFO, with passage of venous blood directly through the defect. This phenomenon of right-toleft shunting decreases in the supine position as the heart assumes a more cephalic position, abating the anatomic changes responsible for it. $^{7}$

Another possible explanation for the direction of the shunt could be the presence of some other associated abnormalities, such as an elongated aortic root or a diaphragmatic paralysis, both of which increase in frequency with aging ${ }^{8}$ and can cause a compression of the right atrium with right-to-left shunting, as has been described before. ${ }^{9}$

PFO is a prevalent condition, affecting $25 \%$ to $30 \%$ of individuals in some series. ${ }^{10}$ Most patients with this defect are asymptomatic, but a transient right-to-left shunt can

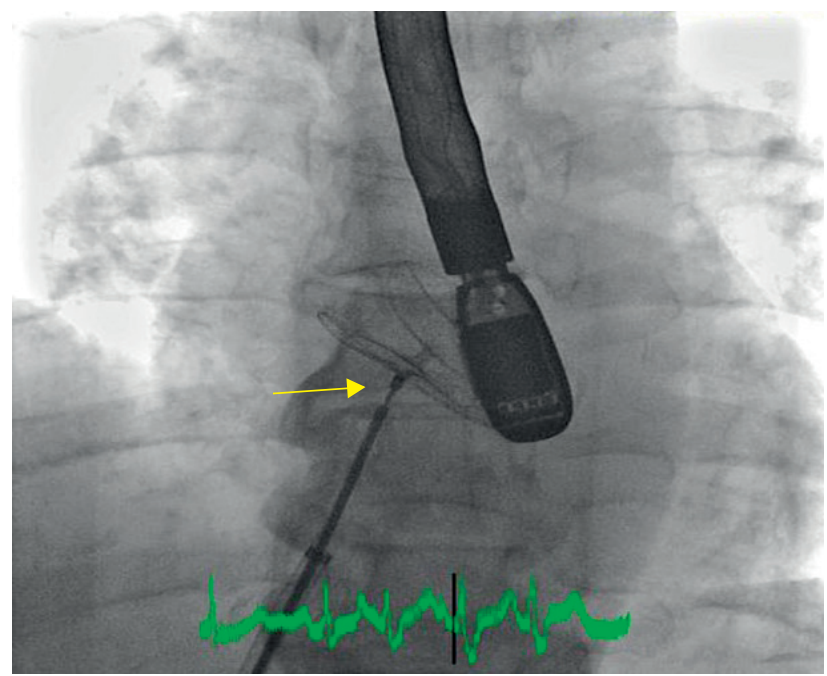

Figure 4 - Fluoroscopy demonstrating percutaneous transcatheter closure of the defect using an amplatzer multifenestrated septal occluder (arrow) occur in up to $92 \%$ of them with manouvers such as coughing or straining. ${ }^{11} \mathrm{~A}$ transoesophageal echocardiography with contrast at rest and during Valsalva manouver is usually considered the best diagnostic test, although transthoracic echocardiography may be useful in patients with good acoustic windows. ${ }^{12}$ Percutaneous transcatheter closure of the PFO is usually regarded as the treatment of choice for these patients, as it is associated with total resolution of the shunt, ${ }^{13}$ as was the case with our patient.

\section{CONCLUSION}

Dyspnea and desaturation are common events in our daily clinical practice. After excluding more common conditions, it is important to consider POS in the differential diagnosis of these symptoms and signs, especially in elderly patients who are more predisposed to present those abnormalities responsible for the inversion of a potential leftto-right shunt. Once POS is suspected, a thorough search for the etiology of this condition should be undertaken, as it may be potentially curable with total resolution of the patients' clinical picture.

\section{PROTECTION OF HUMANS AND ANIMALS}

The authors declare that the procedures were followed according to the regulations established by the Clinical Research and Ethics Committee and to the Helsinki Declaration of the World Medical Association.

\section{DATA CONFIDENTIALITY}

The authors declare having followed the protocols in use at their working center regarding patients' data publication. Informed consent was duly obtained from the patient.

\section{CONFLICTS OF INTEREST}

All authors report no conflict of interest.

\section{FUNDING SOURCES}

This research received no specific grant from any funding agency in the public, commercial, or not-for-profit sectors. 


\section{REFERENCES}

1. Rodrigues P, Palma P, Sousa-Pereira L. Platypnea-orthodeoxia syndrome in review: defining a new disease? Cardiology. 2012;123:1523.

2. Takiguchi $H$, Niimi K, Aoki T, Ogiya R, Ohno $\mathrm{Y}$, Nakazawa G, et al Platypnea-orthodeoxia syndrome caused by a latent atrial septal defect. Intern Med. 2013;52:1809-11.

3. Akin E, Kruger U, Braun P, Stroh E, Janicke I, Rezwanian R, et al. The platypnea-orthodeoxia syndrome. Eur Rev Med Pharmacol Sci. 2014;18:2599-604.

4. Knapper JT, Schultz J, Das G, Sperling LS. Cardiac platypneaorthodeoxia syndrome: an often unrecognized malady. Clin Cardiol. 2014;37:645-9.

5. Jung SY. Transcatheter treatment of atrial septal defect presenting with platypnea-orthodeoxia syndrome. Korean Circ J. 2015;45:169-73.

6. Cheng TO. Mechanisms of platypnea-orthodeoxia: what causes water to flow uphill? Circulation. 2002;105:e47.

7. Alkhouli M, Gagel A, Mathur M, O'Murchu B. Platypnea-orthodeoxia syndrome: an unusual complication of partial liver resection. Intern Med. 2015;54:1067-9.

8. Sanikommu V, Lasorda D, Poornima I. Anatomical factors triggering platypnea-orthodeoxia in adults. Clin Cardiol. 2009;32:E55-7.

9. Maholic R, Lasorda D. Successful percutaneous closure of a patent foramen ovale causing hypoxia in the setting of an elevated hemidiaphragm due to Guillian-Barre syndrome. J Invasive Cardiol. 2006;18:434-5.

10. Hagen PT, Scholz DG, Edwards WD. Incidence and size of patent foramen ovale during the first 10 decades of life: an autopsy study of 965 normal hearts. Mayo Clin Proc. 1984;59:17-20.

11. Meissner I, Whisnant JP, Khandheria BK, Spittell PC, O'Fallon WM, Pascoe RD, et al. Prevalence of potential risk factors for stroke assessed by transesophageal echocardiography and carotid ultrasonography: the SPARC study. Stroke Prevention: Assessment of Risk in a Community. Mayo Clin Proc. 1999;74:862-9.

12. Thanigaraj S, Valika A, Zajarias A, Lasala JM, Perez JE. Comparison of transthoracic versus transesophageal echocardiography for detection of right-to-left atrial shunting using agitated saline contrast. Am J Cardiol. 2005;96:1007-10.

13. Cheng TO. Transcatheter closure of patent foramen ovale: a definitive treatment for platypnea-orthodeoxia. Catheter Cardiovasc Interv. 2000;51:120. 